\title{
Incorporating augmented reality to enrich student learning
}

\section{Ronan T. Bree}

Dundalk Institute of Technology, Ireland

\section{Abstract}

Learning in higher education is now performed across several dimensions, for example: face-to-face in the classroom or practical sessions; engaging with reusable learning objects; online distance learning and virtual learning environments, all represent significant 'places' of learning. With the advent of technology, the incorporation of multimedia resources to complement lecture theory/practical applications is increasingly evident in modules and programmes. However, with these advances come excessive supplementary digital resources that are available to students, often across multiple platforms. The resources can become separated from relevant lecture notes and this disconnection represents a potential block to learning. Augmented Reality (AR) addresses this concern. Through activation via a 'trigger' image placed in a printed handout, students can engage with specific multimedia content in real-time, and more importantly at the appropriate part of their course. Examples of these multimedia resources are pre-existing online, or customised electronic sketch, videos. Each can be made available for repeat viewings at a later stage, empowering students and benefiting self-paced learning and revision. Here, the role and benefit of $A R$ in empowering students with regard to their learning and the steps needed to introduce AR are discussed.

Keywords: Technology Enhanced Learning; augmented reality; reusable learning object; aurasma; quick response code.

\section{Introduction}

Complementing lectures, today's students are often provided with course material/resources on virtual learning environments (VLEs) (Demian and Morrice, 2012). VLE's allow immediate mobile access to view and print online content, in addition to other 
features. However in our digital era, this can have limitations - students may become overwhelmed with large numbers of digital resources and references in VLEs, finding them difficult to handle (Gordon, 2014). With excessive circulation of hyperlinks, online resources residing in multiple locations on top of handwritten lecture notes, students have to spend time locating specific resources and linking them to relevant sections of lecture handouts. Hence it may be difficult for students to find relevant material for learning when they are studying or revising a particular topic - when they need it most. Essentially, learning materials can become separated from each other, with deep learning potentially impacted. To avoid such scenarios, educators should consider the processes they use, consistency across these methods and tools to simplify how students will access this material when needed.

\section{Supporting learning with technology}

There are numerous reports outlining the importance of technology to enrich the teaching and learning experience while supporting personalised learning (Kihlén and Waligorski, 2003; Brouwer and McDonnell, 2009; Mayer et al., 2009; Dunne and Ryan, 2012; Boylan, 2014; EU Commission, 2014; Bright et al., 2015; National Forum for the Enhancement of Teaching and Learning in Higher Education, 2015; Y1Feedback, 2016). Digital applications have the power to engage and motivate learners, assess knowledge and understanding, provide feedback in different formats and provide instant access to a world of accessible theory (Dervan, 2014; Y1Feedback, 2016). However, it is important technology is viewed as a means to encourage or support learning and have an impact, rather than be included to add 'bells and whistles' to a module (Light et al., 2009).

\section{Multimedia/video access}

As part of face-to-face lectures, in addition to providing lecture handouts, educators regularly utilise multimedia technology resources to support or enable learning. The use of video in particular has the power to grab students' attention and motivate learning (Whatley \& Ahmad, 2007; Chua et al., 2015). Learners regularly refer to instructional videos online for demonstrations and procedural guidance (Chan, 2010). Many educators identify online video resources to assist their teaching, while others create their own customised videos with robust effect (Dunne et al., 2015). In most cases, educators provide post-lecture access to multimedia objects via VLEs or e-mail circulation of 
hyperlinks. The intention is to allow self-paced learning to occur via electronic devices. There is a limitation to this approach; if each module educator circulates 10 hyperlinks to multimedia video clips over the course of their module, and the student has 4 modules, this amounts to 40 hyperlinks. Some may reside on a YouTube channel, some circulated as hyperlinks via e-mail or social media and others uploaded to a VLE. For a student to have the ability to search and easily retrieve specific information online when needed can be challenging and we have to consider this limitation and identify a solution. When a student is reviewing a particular topic prior to an exam, a large-scale search operation has to take place. The students have class handouts and their handwritten notes in front of them yet have to search through multiple online locations for the relevant digital resource complementing the topic of interest. In the case of hyperlinks, they don't contain many identifiable clues in their addresses. While there are beneficial avenues for learners and educators to manage increasing number of hyperlinks, for example 'Diigo' (Diigo, 2017) which allows you to keyword label/tag and subsequently search bookmarks in your account (Glynn, 2016), these still fail to directly link the digital content to the relevant paper-based handouts/notes. Hence, educators need to consider this issue and implement solutions - one of which could involve augmented reality (AR) technology.

\section{Engaging with augmented reality (AR)}

AR combines virtual and real-world entities allowing them to interact in real time (Azuma 1997; Garrett et al., 2015). In using AR, virtual objects such as computer graphics can be superimposed or overlaid on real-life 'triggers' (Lukosch et al., 2015). With AR technology, any one-dimensional object can be brought to life, with a new dimension being added, providing its role in student learning with significant potential. While AR adds a new dimension to many walks of life, in education it can provide support and opportunities for communication, learning and understanding (Atherton et al., 2013; Enyedy et al., 2015; Pauly et al., 2015; McMahon et al., 2016).

\section{Implementing AR technology}

As mentioned above, in this digital age, there can be concerns around providing students with large numbers of digital resources/hyperlinks to assist their understanding across programmes. What students critically need is the opportunity to access appropriate video resources at the appropriate time - this is crucial for enabling learning and understanding, 
facilitating assimilation and synthesis of information. This streamlining process can maintain attention, improve understanding and reduce time spent trawling through: hyperlinks; VLE pages; YouTube channels and e-mail inboxes. The integration of AR technology, using apps such as Aurasma (Aurasma, 2017), can help achieve this goal. Aurasma is a freely available app that can be installed on any smartphone. Users can set up a free account online and 'follow' various contributors. The app uses its camera function to scan triggers, referred to as 'Auras' (these are images selected and provided by the educator). Once the camera/scanner identifies an 'aura' trigger, the appropriate video will play within the app, appearing to 'float' above the image being scanned. This is incredibly powerful, as students can access relevant videos for specific topics at the correct time - all directly from their handout or lecture notes. It represents a method for adding structure/organisation of electronic resources. Here, the learner can reap the true intended benefit of the educator including the technology in their teaching and synthesise the information. Customised videos, or online resources can be linked to via the Aurasma App and this can enrich the learning potential of any printed handout.

I introduced AR with undergraduate science students to enrich the teaching and learning of complex scientific processes. Eight videos were recorded (Figure 1 details the technical approaches required for any educator wishing to implement a similar approach with customised sketch videos). These reusable learning objects were comprised primarily of customised electronic sketches recorded on an iPad Pro. From a student viewpoint, the immediate availability of multimedia resources during and after lectures, complementing and enhancing understanding was a welcome addition. During exam preparations, the easily accessed videos represented an ideal revision tool. Correct positioning of the 'trigger' image at the appropriate position in lecture notes empowered the student, allowing viewing of complementary multimedia resources in the right context, essentially bringing the handouts 'to life' and fulfilling deeper understanding. 


\section{Figure 1. A technical overview of the implementation process of AR for customised} videos.

Download the free 'Aurasma', 'Explain Everything' and 'Dropbox' Apps to an iPad Pro tablet device \& set up accounts online where appropriate.

Use 'Explain Everything' app on an iPad Pro with an Apple Pencil to record a customised electronic sketch video (or identify a hyperlink to an appropriate online resource). If a customised video has been created, export the video as an .mp4 file to your dropbox account.

Identify or draw an image that will be used as a 'trigger' image in the lecture handout to activate the playing of the video.

Upload the recorded .mp4 video file and corresponding 'trigger' image to your Aurasma account and ensure the video is set to public (rather than private) to allow others to use.

Pilot videos/technology with a sample student group to identify any concerns or areas of improvements so enhancements can occur in future videos.

Invite students to download the free aurasma app, set up a user account and 'follow' your account (note they must follow your account to see your videos).

Provide students with print out of 'trigger' images (or label on slide handouts provided as a trigger image)

Students will now be able to activate playing of the video using the 'trigger' image.

Certain apps are required to:

- Record and edit your video (Explain Everything).

- Upload and store your final video file (Dropbox).

- Set up the trigger image/video (Aurasma). 
To experience AR, simply download the free 'Aurasma' app on a smartphone, set up a free account, follow the account named 'ronanbree' and scan over the image in Figure 2 (shown below) with the app's camera facility. The appropriate video can then be seen on the smartphone screen. (The video describes the events that occur during the scientific process of DNA replication).

Figure 2. Engaging with augmented reality using Aurasma.

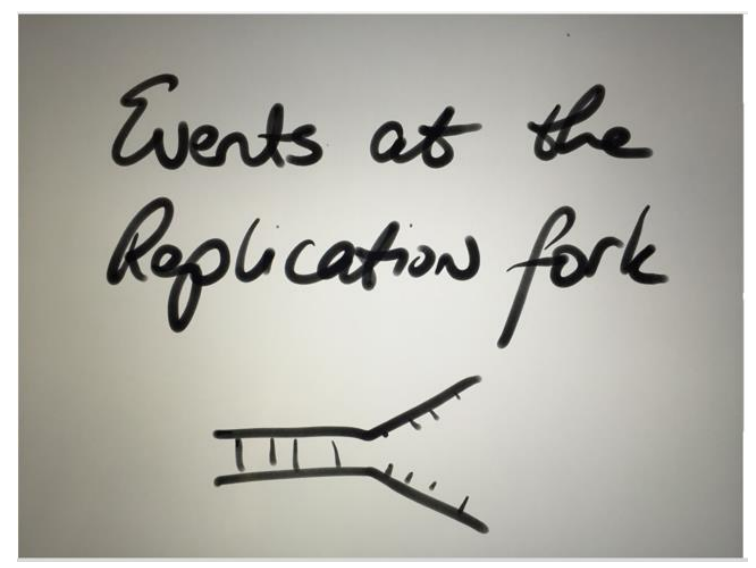

\section{Lecturer experience/viewpoint}

From my point of view, the Aurasma software was extremely user-friendly. Incorporating the use of an Apple iPad Pro and Apple Pencil allowed me to create customised, bespoke electronic sketch videos. These bespoke videos gave me editorial control of content, aligned to the focus of key topics covered in my lectures. For anyone considering Aurasma, some key aspects to consider before getting started would be the orientation of the video (portrait vs. landscape), the quality of the sound playback, the length of the video and the use of customised bespoke sketches versus professionally recorded online resources. As mentioned in Figure 1, I would recommend firstly engaging with a sample learner group to obtain feedback on their viewing/format/preferences. My current goal is to generate and include a wider selection of videos and triggers in lecture handouts, allowing further video viewing alongside relevant course content. Another recommendation for educators is to upload any completed videos to a YouTube channel playlist in parallel. This will avoid any frustration for students with an incompatible mobile device (Garrett et al., 2015). 
One limitation encountered was the requirement for students to set up accounts and follow the educator's account. While this can be bypassed by a "significant software investment" for a 'universal aura', the software providers say this feature is designed for "major campaigns with large exposure" (Aurasma, 2017). However, there are alternatives I am piloting now that possess many of the advantages to the AR approach mentioned above. Implementing Quick Response (QR) codes in lecture handouts will allow students to use free smartphone apps to scan the square shaped barcode, and be 'brought' to the corresponding website/YouTube video with the information of interest (for an example of this, download a QR scanning app to your smartphone and scan the QR code in Figure 3 to view a learning and teaching animation video created by the author).

\section{Figure 3. Using QR barcodes to bring learners to specific online content.}

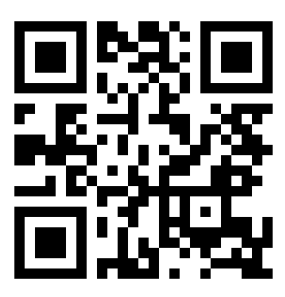

With the introduction of any technology-based approach, another limitation can be the need for expensive equipment. A solution to this is often the use of a smartphone for video capture and editing. The initial investment of time represents the most significant limitation; needed for planning, recording/editing content before uploading and piloting same. In my opinion, the payoff for the investment of time and resource from an educator perspective reaps its reward by enriching learning, helping students access content efficiently, improving understanding and offering hands-on demonstrations of skills, techniques or procedures. AR will be part of our future - now is the time to embrace it in our learning environments.

\section{Conclusion}

The days of spending an entire lecture transcribing notes from an overhead are well and truly behind us. In a digital era, students are living in a world of expanding volumes of information. With material spread across numerous sources, retrieval is resource intensive for students and may confuse, preventing important resources from being located, hampering learning. The structured integration of AR allows students to engage with 
appropriate multimedia efficiently in handouts in class, or at a later stage. This approach allows student self-paced learning to occur, while providing an easy way to access the multimedia resource. AR technology can allow us to trigger instructional videos on pieces of equipment, additional information on background theory or links to practical/clinical skills videos etc. In summary, the introduction of $A R$ in education environments is worth considering, and represents a student-friendly technology intervention that can assist in developing learning and understanding in this new digital era.

\section{Acknowledgements}

The author would like to acknowledge funding which was received from the 'What, Works and Why' initiative which ran in Dundalk Institute of Technology, Dublin City University, Athlone Institute of Technology and Maynooth University sponsored by the National Forum for the Enhancement of Teaching and Learning in Higher Education.

\section{References}

Atherton, S., Javed, M., Webster, S. V and Hemington-Gorse, S. (2013) 'Use of a mobile device app: a potential new tool for poster presentations and surgical education', Journal of Visual Communication in Medicine, 36(1-2), pp. 6-11. http://dx.doi.org/10.3109/17453054.2013.790794

Aurasma (2017) Aurasma (Version: 5.1.2) [Mobile application software]. Available at: http://www.aurasma.com (Accessed: 17 February 2017).

Azuma, R. (1997) 'A survey of augmented reality', Presence: Teleoperators and Virtual Environments, 6(4), pp. 355-385. http://dx.doi.org/10.1162/pres.1997.6.4.355

Boylan, F. (2014) The 12 Apps of Christmas - 2014. Available at: https://the12appsofchristmas.wordpress.com/ (Accessed 23 April 2016).

Bright, P., Lord, B., Forbes, H., Oprescu, F., Barr, N., Downer, T., Phillips, N.M., McTier, L., Simbag, V. and Alla, K. (2015) 'Expert in my pocket: creating first person POV 
videos to enhance mobile learning', Proceedings of the 2015 The Higher Education Technology Agenda Conference. Gold Coast, Queensland 11-13 May.

Brouwer, N. and McDonnell, C. (2009) 'Online support and online assessment for teaching and learning chemistry', in Eliks, I. and Byers, B. (eds.) Innovative methods of teaching and learning chemistry in higher education. London: RSC, pp.123-152.

Chan, Y.M. (2010) Video instructions as support for beyond classroom learning. Procedia Social and Behavioral Sciences, 9, pp. 1313-1318. http://dx.doi.org/10.1016/j.sbspro.2010.12.326

Chua, K.H., Oh, M.Y., Wee, L.K. and Tan, C. (2015) Multimedia-video for learning. Available at: http://arxiv.org/abs/1502.01090 (Accessed: 24 September 2017).

Demian, P. and Morrice, J. (2012) 'The use of virtual learning environments and their impact on academic performance', Engineering Education, 7(1), pp. 11-19. Available at: http://www.tandfonline.com/doi/full/10.11120/ened.2012.07010011 (Accessed: 24 September 2017).

Dervan, P. (2014) 'Increasing in-class student engagement using Socrative (an online Student Response System)', The All Ireland Journal of Teaching and Learning in Higher Education, 6(3), p.180;1-180;13 [Online]. Available at: http://ojs.aishe.org/index.php/aishe-j/article/view/180 (Accessed: 24 September 2017).

Diigo (2017) Diigo (Version 3.3.78) [Online software]. Available at: https://www.diigo.com/ (Accessed: 24 September 2017).

Dunne, J. and Ryan, B. (2012) 'Learning in the science lab: a new approach', Irish Journal of Academic Practice, 1(1), pp. 1-18 [Online]. Available at: http://arrow.dit.ie/ijap/vol1/iss1/2 (Accessed: 24 September 2017).

Dunne, K., Brereton, B., Bree, R. and Dallat, J. (2015) 'Integrating customised video clips into the veterinary nursing curriculum to enhance practical competency training and 
the development of student confidence', The All Ireland Journal of Teaching and Learning in Higher Education, 7(3), pp. 258;1-258;25 [Online]. Available at: http://ojs.aishe.org/index.php/aishe-j/article/view/258 (Accessed: 24 September 2017).

Enyedy, N., Danish, J.A. and DeLiema, D. (2015) Constructing liminal blends in a collaborative augmented-reality learning environment, International Journal of Computer-Supported Collaborative Learning, 10(1), pp. 7-34. https://doi.org/10.1007/s11412-015-9207-1

EU Commission (2014) The Changing Pedagogical Landscape. Available at: http://www.changingpedagogicallandscapes.eu/publications/ (Accessed: 24 September 2017).

Garrett, B.M., Jackson, C. and Wilson, B. (2015) 'Augmented reality m-learning to enhance nursing skills acquisition in the clinical skills laboratory', Interactive Technology and Smart Education, 12(4), pp. 298-314. http://dx.doi.org/10.1108/ITSE-05-2015-0013

Glynn, M. (2016) T1 Step: Organisational Tools: Using Diigo and other Social Media Tools to Support Learning. Limerick Institute of Technology, Take 1 Step Roadshow, 15 March [Video]. Available at: https://www.youtube.com/watch?v=orhM0rxsz8s (Accessed: 24 September 2017).

Gordon, N. (2014) 'Flexible Pedagogies: technology-enhanced learning' [online] The Higher Education Academy. Available at: https://www.heacademy.ac.uk/knowledgehub/flexible-pedagogies-technology-enhanced-learning (Accessed: 24 September 2017).

Kihlén, M. and Waligorski, M. (2003) 'Electronic lab notebooks - a crossroads is passed'. Drug Discovery Today, 8(22), pp. 1007-1009. https://doi.org/10.1016/S1359$\underline{6446(03) 02887-3}$ 
Light, G., Calkins, S. and Cox, R. (2009) Learning and teaching in higher education: the reflective professional. London: Sage Publications Ltd.

Lukosch, S., Billinghurst, M., Alem, L. and Kiyokawa, K. (2015) 'Collaboration in Augmented Reality', Computer Supported Cooperative Work, 24(6), pp. 515-525. https://doi.org/10.1007/s10606-015-9239-0

Mayer, R.E., Stull, A., Deleeuw, K., Almeroth, K., Bimber, B., Chun, D., Bulger, M., Campbell, J., Knight, A. and Zhang, H. (2009) 'Clickers in college classrooms: fostering learning with questioning methods in large lecture classes', Contemporary Educational Psychology, 34(1), pp. 51-57. http://dx.doi.org/10.1016/j.cedpsych.2008.04.002

McMahon, D.D., Cihak, D.F., Wright, R.E. and Bell, S.M. (2016) 'Augmented reality for teaching science vocabulary to postsecondary education students with intellectual disabilities and autism', Journal of Research on Technology in Education, 48(1), pp. 38-56. http://dx.doi.org/10.1080/15391523.2015.1103149

National Forum for the Enhancement of Teaching and Learning in Higher Education (2015) Teaching and learning in Irish higher education: a roadmap for enhancement in a digital world 2015-2017. Available at: http://www.teachingandlearning.ie/wpcontent/uploads/2015/03/Digital-Roadmap-web.pdf (Accessed: 23 February 2017).

Pauly, O., Diotte, B., Fallavollita, P., Weidert, S., Euler, E. and Navab, N. (2015) 'Machine learning-based augmented reality for improved surgical scene understanding', Computerized Medical Imaging and Graphics, 41, pp. 55-60. http://dx.doi.org/10.1016/j.compmedimag.2014.06.007

Whatley, J. and Ahmad, A. (2007) 'Using video to record summary lectures to aid students' revision', Interdisciplinary Journal of Knowledge and Learning Objects, 3, pp. 185196. Available at: http://www.ijklo.org/Volume3/lJKLOv3p185-196Whatley367.pdf (Accessed: 24 September 2017). 
Y1Feedback (2016) Technology-enabled feedback in the first year: a synthesis of the literature. Available at: http://y1feedback.ie/synthesisoftheliterature/ (Accessed: 23 February 2017).

\section{Author details}

Dr. Ronan Bree is a Biochemist/Molecular Biologist with a strong research background in embryo developmental genetics and DNA damage/cancer research. Dr. Bree possesses an MA in Learning and Teaching and is an established researcher in the area of assessment both the in classroom and the practical laboratory. 